\title{
Reflexões sobre o Lugar Social do Índio na Territorrialização/ Desterritorialização promovida pelo Estado no Norte de Mato Grosso do Sul
}

\author{
Beatriz dos Santos de Oliveira Feitosa \\ Universidade Federal de Mato Grosso
}

\begin{abstract}
Resumo: Este trabalho é parte da pesquisa realizada durante o curso de Doutorado em História pela Universidade Federal de Mato Grosso. Para a escrita deste artigo foi selecionado um conjunto de entrevistas arquivadas desde o ano de 2002, que atravessam uma narrativa que tem como preocupação principal a ocupação do território atravessado desde os anos de 1970 pela Rodovia BR-163, com foco na Região Norte do estado de Mato Grosso do Sul. É fundamental ressaltar que tal processo de ocupação é bastante anterior ao marco temporal aqui delineado. Para pensar este processo de ocupação inicial recorremos a documentação que consta nas narrativas de memorialistas da região, ao arquivo das prefeituras dos municípios da Região Norte do estado de Mato Grosso do Sul, ao Relatório Arqueológico produzido pela Usina Hidrelétrica Ponte de Pedra durante a construção da barragem do Rio Corrente no município de Sonora, no ano de 2002. Trabalhamos ainda com as fontes orais, buscando dar visibilidade ao problema dos lugares sociais ocupados pelos indígenas ao longo da constituição daquele território, questão central deste texto.
\end{abstract}

Palavras-chave: Estado; Território; Povos Indígenas. 


\title{
Reflexiones sobre el Lugar Social del Indio en la Territorrialización / Desterritorialización promovida por el Estado en el Norte de Mato Grosso do Sul
}

Resumen: Este trabajo es parte de la investigación realizada durante el curso de Doctorado en Historia por la Universidad Federal de Mato Grosso. Para la escritura de este artículo fue seleccionado un conjunto de entrevistas archivadas desde el año 2002, que atravesan una narrativa que tiene como preocupación principal la ocupación del territorio atravesado desde los años 1970 por la Ruta BR-163, con foco en la Región Norte del estado de Mato Grosso do Sul. Es fundamental resaltar que tal proceso de ocupación es bastante anterior al marco temporal aquí delineado. Para pensar este proceso de ocupación inicial recurrimos a la documentación que consta en las narrativas de memorialistas de la región, al archivo de las alcaldías de los municipios de la Región Norte del estado de Mato Grosso do Sul, al Informe Arqueológico producido por la Usina Hidroeléctrica Puente de Piedra durante la construcción de la vivienda en la ciudad de Sonora, en el año 2002. Trabajamos con las fuentes orales, buscando dar visibilidad al problema de los lugares sociales ocupados por los indígenas a lo largo de la constitución de aquel territorio, cuestión central de este texto.

Palabras clave: Estado; territorio; Pueblos Indígenas.

\section{Reflections on the Social Place of the Indian in the Territorrialization / Desterritorialization promoted by the State in the North of Mato Grosso do Sul}

\begin{abstract}
This work is part of the research carried out during the $\mathrm{PhD}$ course in History by the Federal University of Mato Grosso. For the writing of this article was selected a set of interviews filed since the year 2002, which cross a narrative that has as main concern the occupation of the territory crossed since the 1970 s by Highway BR-163, with focus on the North Region of the state of Mato Grosso do Sul. It is important to emphasize that this occupation process is quite prior to the time frame outlined here. In order to think about this process of initial occupation, we used the documentation contained in the narratives of memorialists of the region, the archives of the municipalities of the municipalities of the Northern Region of the state of Mato Grosso do Sul, the Archaeological Report produced by the Ponte de Pedra Hydroelectric Power Plant during the construction of dam of Rio Corrente in the municipality of Sonora in 2002. We also worked with the oral sources, seeking to give visibility to the problem of the social places occupied by indigenous people throughout the constitution of that territory, a central issue of this text.
\end{abstract}

Keywords: State; Territory; Indian people. 


\section{Introdução}

O bom do caminho é haver volta.

Para ida sem vinda basta o tempo.

Mia Couto/Um rio chamado tempo, uma casa chamada terra

A documentação consultada que faz referência ao processo de ocupação do Norte de Mato Grosso do Sul, refere-se genericamente ao povo Caiapó que habitava originalmente o território. Para escrever sobre um movimento humano marcado por territorializações, desterritorializações e multiterritorializações, recorreu-se a um conjunto documental que ultrapassa os limites das fronteiras impostas pelas disciplinas, o que justifica trabalhar inicialmente com a letra de uma canção no intuito de pensar a dimensão do que foi para os povos indígenas que habitavam aquele território, o contato com outros grupos humanos que chegaram à região a partir do século XVIII.

Na segunda metade do século XX, novos movimentos de ocupação em direção ao interior do Brasil, resultaram em inéditos contatos entre índios e não índios, cujas marcas podem ser lidas nos versos sertanejos de Cacique e Pajé, filhos de agricultores, ambos nascidos em tribo indígena às margens do Rio Vermelho, no município de Rondonópolis-MT e entregues a boiadeiros que passavam pela região devido a uma epidemia de febre amarela.

A dupla "Cacique e Pajé" foi formada em 1978, a gênese da dupla que passou a refletir sobre as questões do sertão, entendido como o espaço que originariamente era ocupado por nações indígenas submetidas pela expansão da fronteira que obedecia lógica diferente de apropriação e uso do solo, tais reflexões traduzidas em sucessos tais como "Caçando e Pescando" e "Deixa o Índio em Paz", guardam relações da proximidade dos compositores com o universo Caiapó. Cacique um dos integrantes da dupla era filho de um cacique da etnia Caiapó, enquanto que o avô paterno havia sido um pajé (curandeiro) da mesma etnia. (CACIQUE \& PAJÉ, 2015).

A recorrência a tal produção cultural que trata do cenário de deslocamento compulsório em face da desterritorialização dos povos indígenas para a manutenção de uma nova lógica, sustentada em cultura do capital, podem ser vistos sob a ótica de protagonistas no processo de eleição de pessoas para a ocupação dos territórios, 


\begin{abstract}
Raio de luz de candeia na baixada ele viu Pensando ser retirante seu bando ele reuniu Mas quando foi atacando numa armadilha caiu Uma descarga de flecha no contra-ataque partiu Do seu bando de capangas não ficou sobreviventes Ele teve a mesma sorte, mas foi morto lentamente Ali não era morada de um sitiante inocente Era uma aldeia de índio todos guerreiros valente Da tribo dos caiapós onde vive a minha gente. (CACIQUE \& PAJÉ, V. 02, 1979).
\end{abstract}

A recorrência ao contato entre os grupos não indígenas, que chegaram ao território na segunda metade do século XX com as populações ameríndias que ali se encontravam no mesmo período, carrega indícios de que personagens históricos foram beneficiados por políticas empreendidas, sobretudo, pelo Governo Federal, amparado no discurso de que tais espaços estavam "vazios", enquanto toda a documentação com a qual tivemos contato aponta a presença dos Caiapó naquele território.

\title{
A Presença indígena negada pela documentação oficial
}

A letra da canção que retrata o sertão como o espaço do conflito, a narrativa de resistência dos povos caracterizados genericamente de "índios", foi objeto do estudo de autores regionais, cujas narrativas obedecem uma lógica pouco apreciada pelos historiadores de ofício, com foco em personagens da política local em um modelo de escrita muito parecida com a formulada pelos metódicos do século XIX, entretanto a documentação presente em tais narrativas permitem a problematização do passado, atributos do historiador de ofício.

Exemplo de tal escrita com viés político e sustentada na concepção da existência de personagens históricas que seriam protagonistas da ocupação daquele território é o trabalho de João Ferreira Neto, (FERREIRA NETO, 2004). Contador na cidade de Coxim, filho de uma elite de comerciantes locais, seu texto transparece a escolha feita por narrar a vida dos grupos que se constituiriam em pioneiros daqueles territórios.

As narrativas sobre a presença de povos indígena na escrita de cunho memorialista não atuam no sentido de mostrar o protagonismo dos Caiapós, Guaicurus, Terenas, Bororos e Paiaguás (LUCÍDIO, 2013)1, mas para dar visibilidade à bravura do conquistador que subjugou grupos que imprimiam resistência ao colonizador. Das quase quinhentas páginas de texto, Ferreira Neto dedica em torno de 10 páginas para tratar da ação dos povos indígenas no

\footnotetext{
${ }^{1} \mathrm{Na}$ tese de doutorado, defendida em 2013, João Antonio Botelho Lucídio aponta um debate no que se refere ao uso no plural para grafar as nações indígenas, alertando que, "desde 1953 na primeira reunião da Associação Brasileira de Antropologia, foram sugeridas normas para a grafia dos etinônimos brasílicos. Segundo essas normas, os substantivos e adjetivos são invariáveis e grafam-se, no caso dos primeiros, com inicial maiúscula e os segundos com minúscula: os Payaguá, os Bororo, a cerâmica karajá, a pintura kadiwéu. Tais deliberações foram publicadas na Revista de Antropologia, Vol.2, no 2, dezembro de 1954." (LUCIDIO, 2013, p.21). Porém, a exemplo da justificativa dada por Lucidio, este artigo se orienta por um formato de escrita acadêmico, portanto, fundamentado pelo uso da norma culta, por este motivo, recorremos ao uso das regras gramaticais vigentes para a grafia dos nomes indígenas.
} 
percurso das monções, diferindo aquelas que foram o "pesadelo das monções" (Caiapós, Guaicurus e Paiaguás) e os que não “importunaram” os viandantes.

As cinco nações que habitavam originariamente o território Sul Matogrossense foram sistematicamente eliminadas ao longo do contato com o colonizador, questão sequer mencionada pelo narrador de "Raízes de Coxim" produção de cunho narrativo sustentado em documentação que mesmo apresentando tal viés político traz possibilidades de criação do cenário ocupado por grupos humanos diversos em diferentes temporalidades. Tais nações foram criando mecanismos de existência/resistência frente à atuação do colonizador, "[...] Em que pese à exploração a que foram submetidos, cada uma das nações, dos grupos ou até os indivíduos que ocupavam aqueles espaços souberam encontrar seu caminho, fosse aceitando alianças com os jesuítas, fosse como administrados, fugidos, ou recompondo-se e resistindo pela força das armas. [...].”(LUCIDIO, ,2013. P. 14).

No Norte de Mato Grosso do Sul, os Caiapós foram a nação indígena mais resistente ao processo de ocupação. Habitavam o território onde inicialmente se formou a cidade de Coxim da qual foram desmembrados os municípios de: Itiquira, Camapuã, Rio Verde do Mato Grosso, Pedro Gomes, Rio Negro, São Gabriel D’Oeste, Costa Rica, Sonora e Alcinópolis, destes os que particularmente nos interessam são os que estão na Região Norte do estado, atravessados pelo traçado da BR-163, símbolo do progresso levado para a fronteira pelo Governo Federal na vigência da ditadura civil militar.

Os Caiapós empreenderam violentas disputas com o colonizador, disso decorreu a extinção dos Bororos naquele território, onde foi formada a cidade de Coxim. As narrativas de Ferreira Neto (2004) e Silveira (1995) apontam que o nome Coxim deriva do dialeto Boróro, com o significado peixe (Cojim=peixe). Por não terem o perfil de guerreiros os Boróros foram utilizados pelos colonizadores como escudos contra a nação guerreira Caiapó o que resultou de sua extinção total (FERREIRA NETO, 2004, P. 88). Isto explica o fato de que toda a documentação dos arquivos da prefeitura municipal de Coxim, que se encontra resumida no histórico do município, disponível na página on line do Instituto Brasileiro de Geografia e Estatística (IBGE), trata da existência inicial dos Caiapós na região.

Os arranjos produtivos foram configurados a partir de uma guerra étnica cuja função foi constituir junto com os novos formatos territoriais, outras realidades humanas, marcadas pela perda de alguns e pelo enriquecimento de outros. Em "Terra Sonâmbula”, Mia Couto ao discutir a guerra no campo literário e, portanto, ficcional, reflete sobre as alterações na geografia e nas relações humanas vividas em Moçambique como resultado das guerras locais,

[...] Farida queria conhecer mais: saber o motivo da guerra, a razão daquele desfile de infinitos lutos. Lembrei as palavras de Surendra: tinha que haver guerra, tinha que haver morte. E tudo era para quê? Para autorizar o roubo. Porque hoje nenhuma riqueza podia nascer do trabalho. Só o saque dava acesso às propriedades. Era preciso haver morte para que as leis fossem esquecidas. Agora que a desordem era total, tudo estava autorizado. Os culpados seriam sempre os outros. (COUTO, 2007. P. 60). 
O olhar literário dirigido por Mia Couto à tragédia humana vivida pela África com as guerras interétnicas, resultantes de um longo processo histórico de expropriação e deslocamento compulsório, ajuda a ler a tragédia humana vivida em solo brasileiro pelas populações de ameríndios que tiveram suas terras usurpadas pelo processo que vem sendo descrito neste estudo e que foi fundamental para a limpeza étnica que se processou na região.

No livro “A Geografia das Lutas no Campo", Ariovaldo Umbelino de Oliveira faz referência ao filme "Avaeté: a semente da vingança” (VIANA, 1985), baseado no episódio real dos anos de 1970, quando um grupo de pistoleiros, a mando de uma colonizadora, massacrou toda a aldeia onde viviam os índios Avaetés na região Amazônica. Este foi um episódio que mostra o cenário de guerra que estava criado no Brasil, por um lado os grupos econômicos capitalizados e de outro as nações que habitavam o território tradicionalmente.

No filme o cozinheiro Ramiro que não coaduna com as ações dos pistoleiros foge do grupo, levando consigo um pequeno índio Avaeté, as duas personagens são importantes na trama porque foi Ramiro quem denunciou o massacre às autoridades e à imprensa.

As questões referentes à concentração de terras no Brasil e como decorrência no estado de Mato Grosso do Sul impuseram aos grupos indígenas o deslocamento compulsório e a perda de territórios. É importante ressaltar a diferença de concepção de terras para o indígena em relação ao sentido dado pela sociedade abrangente, Fernandes aponta,

\section{[...] é importante perceber que as sociedades indígenas têm sobre a terra um conceito diferente do nosso. Para nossa sociedade, a terra é uma mercadoria, um bem de capital passível de compra e venda. Ela pertence a pessoas, não a um povo; portanto se constitui em propriedade privada e somente tem direitos sobre a terra quem é seu proprietário. (FERNANDES, 1993, p. 80).}

A referência à questão indígena é fundamental no sentido de apontar a existência de processos de exclusão humana resultantes da política de colonização empreendida no Brasil pós 1970. As consequências históricas da concentração de terras e de renda também atingiram, sobremaneira, os povos indígenas do Norte de Mato Grosso do Sul.

No ano de 2002 por ocasião da construção da hidrelétrica Ponte de Pedra no Rio Corrente na região do município de Sonora, foi produzido um relatório arqueológico que apontou a existência de grupos humanos na região há pelo menos 3.500 anos, portanto, como já tratado, grupos indígenas já habitavam este território. A ausência dessas populações na documentação mais recente é indício de sua eliminação no processo de contato com o colonizador. 


\title{
Mapa I: Território de Estudo
}
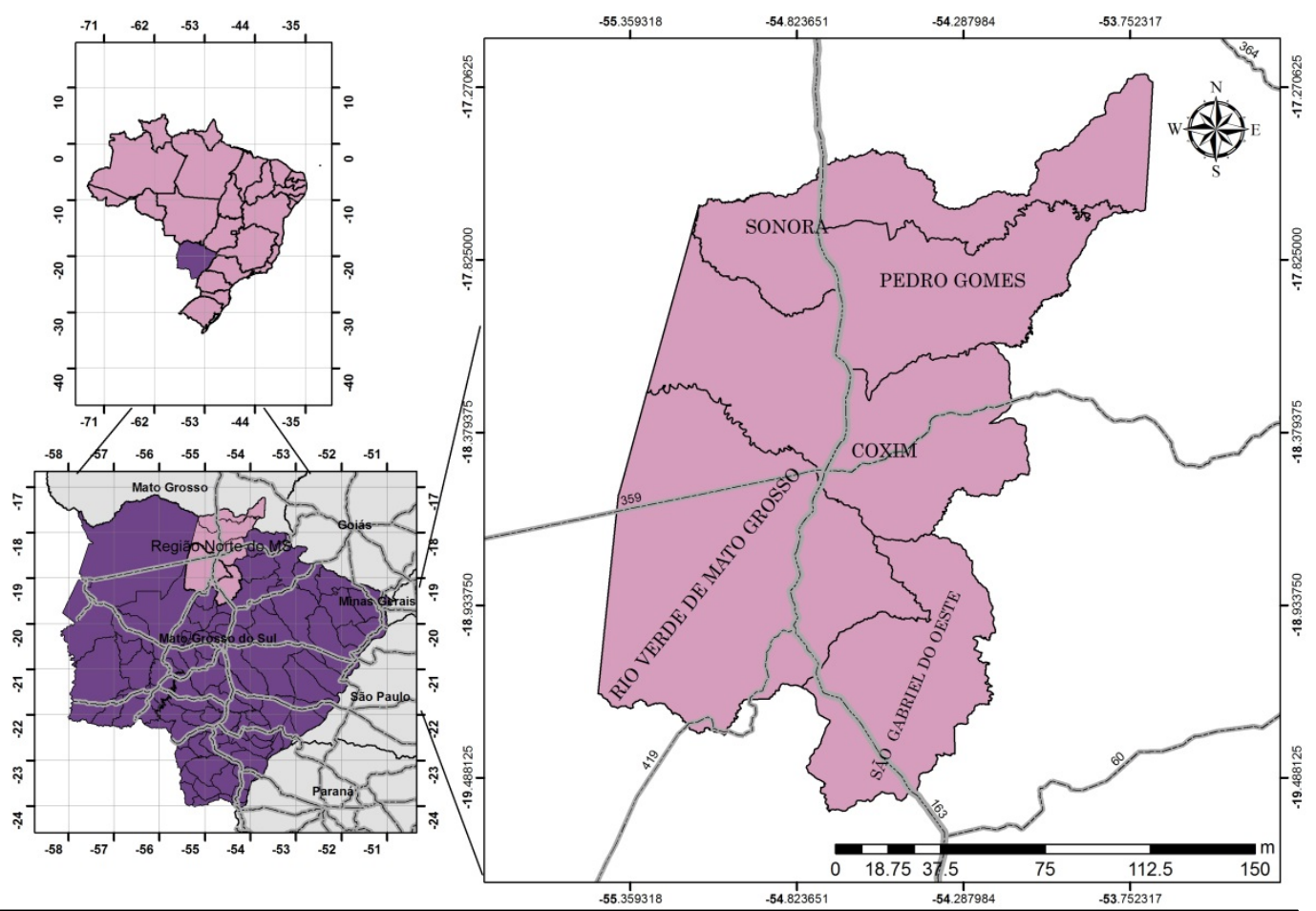

Figura 1 - Mapa I: Municípios de estudo atravessados pelo eixo da Rodovia BR 163

Fonte: Dados Utilizados: IBGE (2010); DNIT (2016). Estagiária do setor de cartografia da UFMT/Rondonópolis, OLIVEIRA (2016) TATIANE DUARTE SILVA OLIVEIRA

Outra questão importante a se destacar no intuito de problematizar o conceito de território indígena, é que tais territórios extrapolam o limite das terras efetivamente ocupadas por eles, assim mesmo que não habitassem parte da região, a área se constituía em espaço econômico e cultural, por onde se deslocavam,

\begin{abstract}
Falar em território indígena significa dizer que este é um espaço da sobrevivência e reprodução de um povo, onde se realiza a cultura, onde se criou o mundo, onde descansam os antepassados. Além de ser um local onde os índios se apropriam dos recursos naturais e garantem sua subsistência física é, sobretudo, um espaço simbólico em que as pessoas travam relações entre si e com seus deuses. (...) a apropriação de recursos naturais não se resume em produzir alimentos, mas consiste em extrair matéria-prima para a construção de casa, para enfeites, para a fabricação de arcos, flechas, canoas e outros e, ainda em retirar as ervas medicinas que exigem determinadas condições ecológicas para vingarem. (FERNANDES, 1993, p. 81).
\end{abstract}

A partir desta concepção de território indígena, deduz-se que, mesmo não existindo aldeias nos municípios estudados e no período compreendido pelo recorte temporal escolhido, quando por ocasião da ocupação pelo capital, havia a possibilidade dessas terras se constituírem em território indígena, pois "[...] Para que um povo possa viver e se reproduzir, necessita de muito mais terras do que as utilizadas para o plantio. E é justamente esse espaço da sobrevivência, 
com tudo que ele implica, que denominamos território "(FERNANDES, 1993, p. 81).

Além de terem seus territórios apropriados por projetos de colonização amparados na ótica de que tais espaços eram "vazios demográficos"2 os descendentes desses povos tiveram sua força de trabalho explorada em fazendas da região desempenhando atividades no corte de cana-de-açúcar, até o ano de 1995. De acordo com Fernandes, esse tipo de atividade, levou à criação de projetos econômicos, a partir dos quais os índios não precisavam mais deixar suas terras para trabalharem em fazendas, de acordo com seu relato:

\begin{abstract}
Os projetos econômicos também são justificados pela venda da força de trabalho fora dos limites da aldeia. Essa incorporação de índios no mercado de trabalho é de fato muito problemática, pois em geral são maltratados pelos patrões, recebem pouco, comem mal e, muitas vezes, são pagos com bebida. Os projetos então seriam uma alternativa viável para proteger essas populações dos maus tratos e da exploração que são vítimas quando trabalham como assalariados; através desse mecanismo, não seria necessário sair da aldeia para conseguir dinheiro para comprar os bens que desejam, pois em tese a renda dos projetos seria revertida para os que nele trabalharam. (FERNANDES, 1993, p. 100).
\end{abstract}

Em entrevista com o ex-prefeito (SIMÕES, 2012) do município de Sonora, ao questionarmos sobre a ausência da FUNAI em um município onde até o ano de 1995 (período em que era gestor) a prática de utilização do trabalho indígena no corte de cana era comum, o mesmo afirmou que essas eram populações que estavam na cidade de forma temporária, portanto diante da inexistência de nações indígenas na região, não haveria necessidade da presença do órgão que os representasse.

A prática do trabalho temporário mascara tanto a presença de povos indígenas naquele período, quando os dados sobre desemprego posteriormente, pois a sazonalidade não permite entender como população da cidade os trabalhadores que migravam no período de safra da cana de açúcar.

Em entrevista concedida da no dia 22 de setembro de 2010, pela senhora Francisca, nos foi informado sobre a utilização do trabalho de índios que vinham da cidade de Miranda, para trabalharem no corte da cana, até o ano de 1995. Ficavam alojados por até quatro meses em habitações temporárias, fora do perímetro urbano numa estrutura contendo quatro barracões grandes, onde se organizavam em grupos, este era o espaço em que se desenvolviam todas as atividades domésticas e de lazer.

Outro entrevistado que trabalhou para a Usina Sonora no município de Sonora desde a fase em que a mesma foi implantada na região afirma,“[...] a gente fazia 2-3-4 barraco pra índio, cada grupo num barraco [...] aí depois fizeram uns barracão bem feito, de tijolo, coberto de teia, aí os índio ficava ali”. (ELMÍNIO, 2009).

“Ao passarmos pela estrada de acesso podíamos vê-los jogando futebol ou tomando banho em um riacho que passa próximo ao lugar onde ficavam os

\footnotetext{
2 Dentre a documentação que possibilita contestar a percepção de um "Vazio Demográfico", ressignificado por inúmeros governos ao longo da história do Brasil, podemos destacar o "Relatório Arqueológico" produzido pela Ponte de Pedra Energética, que aponta a presença de grupos humanos em períodos remotos (há indícios da presença humana de pelos menos 3 mil e quinhentos anos), esse território de ocupação recente motivada pela cultura do capital, pode ter sido um dos motivos que levaram a mudança dos grupos indígenas para outras regiões.
} 
alojamentos", relatou Dete, moradora de uma fazenda da região. Ainda "eles não eram autorizados a visitarem a cidade porque podiam beber e fazer arruaça na cidade" conclui a entrevistada.

Em entrevista com um grupo de índios Terenas ainda em 2002, período em que estavam acampados próximo à cidade de Rondonópolis, momento em que haviam fechado a rodovia BR 163 e que reivindicavam terras para a construção de uma aldeia, foi relatado que em algumas usinas de Mato Grosso do Sul que utilizavam o trabalho indígena, o mesmo era intermediado pelo "gato"3. Esses aliciadores com a omissão da FUNAI contatavam a população indígena e os transportava até os canaviais, no Norte de Mato Grosso do Sul. Haviam empresas de ônibus que eram contratadas para buscar esses grupos nos municípios de Aquidauna, Miranda, Bodoquena, Nioaque e Terenos. Centenas de trabalhadores indígenas se tornavam migrantes sazonais, permanecendo na região durante o período de corte da cana de açúcar.

Essas narrativas traduzem a exploração humana que culminou na formação de cidades no Extremo Norte de Mato Grosso do Sul, constituindo-se em busca de sentidos possíveis para a narrativa proposta. A documentação com que trabalha o historiador, constitui-se em uma espécie de palimpsesto, metáfora utilizada pelos gregos ao se referirem à reutilização de pergaminhos utilizados mais de uma vez para a escrita, nos quais coexistiam narrativas de tempos históricos diferenciados, tal metáfora foi apropriada por Pesavento para pensar sobre a disposição do historiador em olhar para o passado das cidades, caberia ao estudioso estabelecer sentidos possíveis entre as diversas temporalidades presentes nos palimpsestos, neste caso a escrita sobre a história das cidades,

[...] nesta cadeia de sentidos possíveis da cidade palimpsesto, é indispensável recorrer à idéia do tecido, onde os diferentes fios se articulam em trama na montagem das camadas superpostas. Neste caso, é o autor/tecelão da cidade imaginária que deve construir enredos, descobrir caminhos e apresentar a composição da trama. (PESAVENTO, S/D, p. 28)

A busca por tais sentidos não se apresenta como tarefa fácil uma vez que existem silêncios sobre o passado para o qual o historiador lança seu olhar. A questão do trabalho indígena na região é alvo de tais silêncios. Para construir uma "cadeia de sentidos" para tal argumentação a respeito da exploração indígena, recorremos a depoimentos de moradores da região que trazem em suas lembranças a presença dessas personagens que pareciam ocupar um cenário alheio ao seu, o imaginário da população local acerca do modo de vida indígena não condizia com a forma como viam estes grupos nos arredores da cidade em princípios dos anos de 1990, as narrativas apontam para uma confusão entre tempos históricos, "várias vezes passávamos pela estrada que leva ao sumidouro4 e os víamos banhando no riacho próximo aos barracões.” (SILVA, 2009).

3 "Gato" é a denominação regional para o agenciador de mão de obra, que geralmente superexplora os trabalhadores.

4 Acidente geográfico no Rio Corrente onde a água some em sulco gigantesco no solo, voltando ao curso normal depois de percorrer em torno de $2 \mathrm{Km}$ pelo subterrâneo. 
O conceito índio traz uma relação entre passado e presente na medida em que para as pessoas que tiveram contato com os trabalhadores indígenas, a presença de um ser mitológico distante do tempo no qual estão inseridos não condiz com as práticas de todos os matizes, especialmente a prática econômica. A tendência das pessoas é negar a participação dos indígenas em um cenário de desenvolvimento econômico que não condiz com a visão de indígena que lhes foi introjetada ao longo da vida, no universo de estereótipos construídos acerca de uma determinada figura de índio, estes personagens não cabem nos cenários que ocupam,

A história dos conceitos põe em evidência, portanto, a estratificação dos significados de um mesmo conceito em épocas diferentes. Com isso ela ultrapassa a alternativa estreita entre diacronia ou sincronia, passando a remeter à possibilidade de simultaneidade da não simultaneidade que pode estar contida em um conceito. (KOSELLECK, 2006, p. 115).

As relações de trabalho também ganham novos atributos quando grupos humanos têm seus status alterados pela forma como o capital se apropria das atividades humanas. Os indígenas do acampamento Terena aludido que se dispuseram a falar sobre o assunto, relataram o quanto o trabalho era cansativo naquelas usinas. Os que não ficavam acampados tinham que levantar às três da manhã para embarcar em caminhões que os levavam até a usina. Todos os entrevistados deixaram transparecer a seguinte situação: “[...] o que se ganhava mal dava para o próprio sustento e da família, sendo que na maioria das vezes algumas usinas do Mato Grosso do Sul, contratavam inclusive o trabalho de mulheres e crianças indígenas para o trabalho nos canaviais." Relatou dona Joana (2002), que concedeu entrevista ao lado do marido Aristides, afirmando ter trabalhado na execução desta tarefa e contou o quanto era cansativo e mal remunerado.

A exploração do trabalho foi a tônica da constituição desses territórios. Em 1984 dois jornais que circulavam pelo estado de Mato Grosso do Sul em editorial do "Correio do Estado" daquele ano, uma das matérias de capa tem o tema "Denunciada semiescravidão em destilaria de Pedro Gomes",

\footnotetext{
Em seu depoimento à Fetagri, Henrique Rosa de Oliveira relatou que no último sábado, após o jantar, foi falar com José Divino informando-o que não queria mais trabalhar e pretendia receber o salário para ir embora. Como resposta recebeu uma facada do capataz, que atingiu o seu antebraço esquerdo, sendo agredido em seguida a socos e pontapés por quatro “capangas”. (CORREIO DO ESTADO, 1984, p. 5).
}

A denúncia de escravidão foi destaque também em 29 de março de 1984 no "Jornal da Manhã", que tratou além das torturas cometidas contra trabalhadores por agentes em serviço na fazenda da Companhia Sonora Estância, da existência de galpões sem nenhuma condição de higiene em que ficavam alojados os trabalhadores, depois de serem agenciados pelos "gatos" nas cidades de origem "a maioria destas pessoas que estão lá, são levadas pelo gato, após várias promessas, entre as quais de um alto salário”, nas palavras do trabalhador vítima de escravidão. As narrativas sobre a existência de galpões em que ficavam os índios agenciados no Sul do estado remetem a possibilidade de 
submissão à condição degradante de trabalho imposta a esta população em fazendas da região.

Levando-se em conta que para os índios o conceito de terra é diferente do conceito nas sociedades capitalistas, em que a terra se torna mercadoria, ou seja, um bem capitalizado, passível de compra e venda que se constitui em propriedade privada na qual apenas o proprietário é quem tem direito, apreende-se a violência que envolveu as novas configurações territoriais impostas ao Norte de Mato Grosso do Sul.

Essa questão foi trabalhada por Oliveira (1994), que abordou o funcionamento da agricultura sob a égide do capitalismo, tratando como era a agricultura no regime feudal e o que mudou na produção agrícola na transição para o sistema capitalista. Segundo o autor a renda da terra se tornou capitalizada e sujeita ao capital e ainda às consequências da industrialização da agricultura. Para o autor, a única alternativa para os problemas na agricultura brasileira é a superação do modo de produção capitalista.

Considerando a forma dos indígenas conceberem a terra, diferenciando-a entre a de trabalho e a sagrada, esse tipo de trabalho que lhes foi imposto para manter o mínimo necessário à sobrevivência foi, uma violência cometida em função de um modelo de produção altamente elitista, desonesto e injusto. O que foi imposto a contingentes humanos descapitalizados nestes locais de expansão de uma cultura do capital, foi um processo de desterritorialização, que os obrigou a novas mudanças em busca de condições de existência, deixando de pertencer a um determinado território, que lhes foi negado.

A tese de Haesbaert é que o Estado brasileiro atuou na função de desterritorializador, obrigando os trabalhadores a uma busca constante por reterritorialização, ao manter ligações com os vários lugares por onde passam ao longo de suas trajetórias tais grupos humanos passam por um processo de multiterritorialização, tais questões podem ser lidas sob a ótica da produção de Mia Couto que pensa no campo da literatura em questões que dizem muito acerca das desterritorializações pelas quais os seres humanos passam ao longo da existência.

No livro "Um rio chamado tempo, uma casa chamada terra", Mia Couto, utilizando-se de uma narrativa sem pretensões de realidade, mas que diz muito acerca da história e das pessoas no tempo, trata de um lugarejo chamado "Luardo-Chão", de onde todos os moradores queriam partir e de onde todas as fugas empreendidas caminhavam no sentido de uma busca por outros lugares, tal situação transparece na fala de "Abstinêncio", tio da personagem central "Mariano" que retorna ao lugar depois de anos, por ocasião da morte do avô, "Você foi daqui de Luar-do-Chão. Esta é a minha maneira de me ir embora, entende?”, tal diálogo se dá quando Mariano surpreende o tio e descobre o comportamento noturno que difere do "tio Abstinêncio", que conhecera a vida toda e que se apresentava durante o dia. Esta escrita denuncia a busca empreendida pelos humanos que os afasta de suas origens e os reconstrói mediante o estabelecimento de novas relações. Na narrativa de Mia Couto o rio 
separa o lugar conhecido, espaço de nascimento e de perpetuação das tradições, do horizonte desbravado pelo aventureiro que se dispõe atravessá-lo,

Nenhum país é tão pequeno como o nosso. Nele só existem dois lugares: a cidade e a Ilha. A separá-los, apenas um rio. Aquelas águas, porém, afastam mais que a sua própria distância. Entre um e outro lado reside um infinito. São duas nações, mais longínquas que planetas. Somos um povo, sim, mas de duas gentes, duas almas. (COUTO, 2003, p. 18).

Os deslocamentos humanos impõem alterações em trajetórias pessoais, motivadas por fatores especialmente de ordem econômica. No que se refere aos deslocamentos ocorridos no Brasil no pós 1970, para além de uma transformação que se dá no campo pessoal, houve também um processo de alteração dos espaços, "[...] Esta terra começou a morrer no momento em que começamos a querer ser outros, de outra existência, de outro lugar. Luar-doChão morreu quando os que a governam deixaram de a amar. Mas a terra não morre, nem o rio se suspende."(COUTO, 2003,p. 195).

Tais narrativas presentes nos diálogos propostos por Mia Couto podem ser lidos em sintonia com as reflexões feitas por Haesbaert em "O mito da Desterritorialização”. Dentre os vários elementos que fascinam na escrita de Haesbaert, está a simbiose entre processos que se dão inicialmente no campo pessoal para em seguida serem lidos sob a ótica de relações mais amplas e complexas. No prólogo da referida obra o autor faz uma digressão a respeito das sensações vividas por um menino na tenra idade em condição de mudança da família,

[...] voltei no caminhão da mudança. Teria de ficar alguns meses para acabar os estudos. Aos oito anos de idade, morando com desconhecidos, uma nova territorialização era preciso. Lembro quanta falta sentia da família e como tudo ali tinha cheiros, sabores e cores completamente outros. Até descansar ficava mais difícil. Era como se fôssemos obrigados a reconstruir um lar, um território, aos oito anos. Mas logo as férias, o retorno ao campo, àquele "rancho" de sapé e chão batido, fogão de chapa de ferro e concreto, açude para buscar água. E reencontros muitos, incluindo os irmãos que estudavam com os avós na "cidade grande". (HAESBAERT, 2012, Prólogo).

Os diálogos aqui propostos entre literatura vista como a narrativa da ficção e outras narrativas presentes no campo histórico, geográfico, sociológico e antropológico, não tem nenhuma pretensão de objetividade, especialmente por entender a sintonia com questões levantadas por Larrosa que as narrativas encontram-se "[...] Distanciados de qualquer pretensão de objetividade, de universalidade ou de sistematicidade, e inclusive de qualquer pretensão de verdade, nem por isso renunciam a produzir efeitos de sentido.” (LARROSA, 2013, p. 7).

A negação da territorialidade ao indígena, como resultado de opções do Estado brasileiro são perceptíveis por meio do diálogo com o conceito de tempo, que permite problematizar a forma que grupos distintos, ocupam temporalidades também distintas e de como essas temporalidades diversas passam a ocupar um mesmo espaço regido por uma lógica alheia a muitos dos personagens que ocupam tais cenários, tendo em vista que, 


\begin{abstract}
O homem se faz ao se desfazer: não há mais do que risco, o desconhecido que volta a começar. O homem se diz ao se desdizer, no gesto de apagar o que acaba de ser dito, para que a página continue em branco. Frente à autoconsciência como repouso, como verdade, como instalação definitiva na certeza de si, prende a atenção ao que inquieta, recorda que a verdade costuma ser uma arma dos poderosos e pensa que a certeza impede a transformação. (LARROSA, 2013, p. 41).
\end{abstract}

Consciente da impossibilidade de atingir a "verdade dos fatos", pretensão inclusive relegada aos Metódicos5 do século XIX, que ganha muito da produção historiográfica, especialmente didática em momentos adiantados do século XX, as narrativas aqui empreendidas devem ser lidas sob a ótica do humano, cujos processos de desterritorialização e deslocamento forçado o afetaram em sua constituição histórica, a dinâmica histórica de ocupação não indígena no Norte de Mato Grosso do Sul, contraria a lógica daqueles que por algum motivo permaneceram na Luar-do-Chão, narrada por Mia Couto, "Que ele era como a montanha, prossegue. Tinha raiz mais funda que o mundo. Mas às vezes lhe raspava a asa de um sonho - e ele deslugarejava" (COUTO, 2003, P. 120).

Essa quase necessidade humana de se "deslugarejar", foi amplamente estimulada no período em estudo, alimentando sonhos que se traduziram em perdas para muitos e em enriquecimento fácil para poucos, os espaços aqui pensados foram sendo reorganizados em função dos movimentos de desterritorialização. As reflexões de Haesbaert, referente a constituição e perda de territórios passa pelas interpretações dadas por Marx à questão, que teria sido o primeiro teórico a dar ênfase ao papel desterritorializador exercido pelo capital,

\begin{abstract}
Em seu discurso, a ausência do termo não impede a profunda análise das formas com que o modo de produção capitalista "desterritorializa" os modos de produção preexistentes para reterritorializar segundo sua própria dinâmica. A expropriação do campesinato, transformado em trabalhador "livre" em meio a fenômenos como a apropriação privada da terra e a concentração fundiária, e, no outro extremo da pirâmide social, a velocidade com que os estratos mais privilegiados da burguesia destroem e reconstroem o espaço social, sob o famoso dito de que "tudo que é sólido desmancha no ar, tudo que é sagrado é profanado", seriam as referências mais marcantes do movimento de des-re-territorialização capitalista.( HAESBAERT, 2012, p. 175).
\end{abstract}

Tal digressão ao pensamento marxista na busca pela problematização de um passado que se presentifica, é resultado do esforço que viemos empreendendo neste estudo, de apontar a dinâmica dos tempos históricos no ofício do historiador, o que permite afirmar que esforços teóricos empreendidos no século XIX não devem ser descartados por modismos historiográficos. É fundamental compreender a historicidade da produção no campo da História, para não ser ingênuo a ponto de descartar esforços teóricos riquíssimos.

Ao pensar a desterritorialização, Haesbaert promove importante interlocução entre pensadores que não comungam das mesmas matrizes paradigmáticas, o resultado é um estudo que tem muito a contribuir para as pesquisas sobre o território, que se traduzem em uma necessidade em olhar

${ }^{5}$ Referência a Escola Histórica Metódica, especialmente nos estudos científicos realizados no campo da História ocorridos na Alemanha cuja figura central, da chamada "Escola Científica Alemã", foi Leopold Von Ranke, que defendia a História como uma ciência objetiva que se ocupava de narrativas sustentadas na documentação oficial que daria conta de fatos "tais como realmente aconteceram". 
para o sofrimento do "outro", especialmente quando integra o que somos, o que nos constitui. "[...] Era ela que estava vendo sombras? Ou seriam os demais que já nada enxergavam, doentes dessa cegueira que é deixarmos de sofrer pelos outros?" (COUTO, 2002, p. 136).

A atuação estatal que reconfigurou territórios indígenas, promovendo eliminação étnica, deve ser visibilizada por meio da pesquisa acadêmica, dando condições para algo mais que a capacidade humana de sofrer pelos outros, mas para permitir que o acesso à constituição histórica desses povos se traduza em possibilidade de reivindicar direitos, tão cara em tempos de retrocesso nos avanços históricos acessados pelos povos indígenas.

\section{Considerações Finais}

O processo que conduz os sujeitos históricos à reterritorialização, afeta muitas vidas e foi para narrar estas vidas afetadas que este texto foi escrito. Os caminhos migrantes dos desterritorializados do progresso foram os descaminhos históricos da formação social no Brasil, cujos efeitos são tragicamente sentidos pelos povos indígenas da contemporaneidade.

O intuito deste artigo foi contribuir com a reflexão sobre os lugares sociais atribuídos a diferentes grupos humanos ao longo da constituição do território brasileiro e para a compreensão histórica da ocupação do Norte de Mato Grosso do Sul.

Os diálogos com a literatura, especialmente com a produção de Mia Couto, presentes ao longo da narrativa, foi uma forma encontrada para imprimir certa leveza à escrita de um texto cuja opção foi a dureza da negação humana. Ao tratar da constituição dos territórios e da questão do acesso a terra no Brasil, o foco foram às políticas empreendidas pelo Governo Federal que ao promover o acesso diferenciado aos espaços, contribuiu para a desterritorialização dos povos indígenas.

\section{Bibliografia}

COUTO, Mia. Terra Sonâmbula. São Paulo, Companhia das Letras, 2007.

COUTO, Mia. Um Rio Chamado Tempo, Uma Casa Chamada Terra. São Paulo: Companhia das Letras, 2003.

FERNANDES, Joana. Índio: esse nosso desconhecido. Cuiabá: Editora da UFMT, 1993 .

FERREIRA NETO, João. Raízes de Coxim. Campo Grande, MS: EdUFMS, 2004 .

HAESBAERT, Rogério. O Mito da Desterritorialização: do "fim dos territórios" à multiterritorialidade. 7. Ed. Rio de Janeiro: Bertrand Brasil, 2012. 
KOSELLECK, Reinhart. Futuro Passado: contribuição à semântica dos tempos históricos. Tradução de Wilma Patrícia Maas \& Carlos Almeida Pereira. Rio de Janeiro: Contraponto: Ed. PUC-Rio, 2006.

LARROSA, Jorge. Pedagogia Profana: danças, piruetas e mascaradas. Tradução de Alfredo Veiga Neto. 5. Ed. Belo Horizonte: Autêntica Editora, 2013.

LUCIDIO, João Antonio Botelho. “'A Ocidente do Imenso Brasil”: as conquistas dos rios Paraguai e Guaporé (1680-1750)”. Tese de Doutorado. Lisboa: mimeo, 2013 .

OLIVEIRA, Ariovaldo Umbelino de. A Geografia das Lutas no Campo. 6. Ed. São Paulo: Contexto, 1994.

SILVEIRA, Ronan Garcia da. História de Coxim. Campo Grande, MS: Editora Ruy Barbosa, 1995.

PESAVENTO, Sandra Jatahy. "Com os olhos no passado: a cidade como palimpsesto”. Revista Esboços, n. 11, UFSC.

\section{Documentos}

CACIQUE E PAJÉ, Guerreiro Caiapó, Álbum Caçando e Pescando, V. 02, 1979.

VIANA, Zelito (Dir.). Avaeté - semente da vingança. Brasil: Embrafilme, 1985.

Denunciado Semi-Escravidão em Destilaria de Pedro Gomes. Correio do Estado. Ano XXXI, n. 9.252, março de 1984. P. 05.

\section{Entrevistas}

Entrevista concedida em Maio de 2002, por Joana, índia Boróro acampada na BR 163, próximo à cidade de Rondonópolis.

Sr. Elmínio Manoel Barros. Entrevista concedida em agosto de 2009.

Sra. Maria Odete da Silva. Entrevista concedida em agosto de 2009.

SILVA, Maria Odete da (Moradora de uma fazenda no município de Sonora). Entrevista. [Junho de 2009]. Entrevistadora: Beatriz dos Santos de Oliveira Feitosa.Sr. Luís Carlos Simões. Entrevista concedida em Maio de 2012. 